\title{
Silencing Bmi-1 expression by RNA interference suppresses the growth of laryngeal carcinoma cells
}

\author{
XIAO-BAO YAO $^{1^{*}}$, XIAO-XIA WANG ${ }^{12^{*}}$, HUI LIU $^{3}$, SHAO-QIANG ZHANG ${ }^{1}$ and HONG-LIANG ZHU ${ }^{1}$ \\ ${ }^{1}$ Department of Otolaryngology-Head and Neck Surgery, The First Affiliated Hospital, School of Medicine, \\ Xi'an Jiaotong University, Xi'an, Shaanxi 710061; ${ }^{2}$ Department of Otolarynology, 451 Hospital \\ of Chinese People's Liberation Army, Xi'an, Shaanxi 710054; ${ }^{3}$ Department of Otolaryngology, \\ Shaanxi Provincial People's Hospital, Xi'an, Shaanxi 710068, P.R. China
}

Received December 12, 2012; Accepted February 26, 2013

DOI: $10.3892 / \mathrm{ijmm} .2013 .1312$

\begin{abstract}
The aim of this study was to investigate the effect of a B-cell-specific MLV integration site-1 (Bmi-1) RNA interference (RNAi) expression vector on the proliferation and invasiveness of laryngeal carcinoma. We constructed a lentiviral vector expressing Bmi-1-specific short hairpin RNA (shRNA), and transfected it into HEp-2 cells. Bmi-1 gene expression was detected by real-time RT-PCR and western blot analysis. We used flow cytometry and TUNEL assay to analyze the apoptosis of transfected cells, and examined cellular growth in vitro by MTT assay. We established an animal model and evaluated the therapeutic effects of small interfering RNA (siRNA) against Bmi-1. siRNA against Bmi-1 significantly knocked down Bmi-1 expression in HEp-2 cells, induced cell cycle arrest at the G1 phase, inhibited cell proliferation and promoted cell apoptosis. Lentiviral Bmi-1-shRNA vector transfection also significantly reduced cell migration. The formation and growth rate of xenograft tumors in mice transfected with siRNA against Bmi-1 was significantly reduced. The loss of mitochondrial membrane potential, the release of cytochrome $c$ from the mitochondria into the cytosol, and the increased activity of caspase-3, -8 and -9 occurred concomitantly with the inhibition of Bmi-1. Our data indicate that siRNA against Bmi-1 significantly suppresses tumor growth and induces apoptosis in vitro and in vivo.
\end{abstract}

\section{Introduction}

Laryngeal carcinoma is a common head and neck malignancy with high incidence, accounting for approximately

Correspondence to: Professor Xiao-Bao Yao, Department of Otolaryngology-Head and Neck Surgery, The First Affiliated Hospital, School of Medicine, Xi'an Jiaotong University, Xi'an, Shaanxi 710061, P.R. China

E-mail: xiaobaoyaocn@126.com

${ }^{*}$ Contributed equally

Key words: apoptosis, cancer gene therapy, small interfering RNA, B-cell-specific MLV integration site-1
$2.4 \%$ of new malignancies worldwide each year $(1,2)$. Despite extensive application of different treatment modalities, invasion and metastasis remain the main causes of mortality for laryngeal squamous cell carcinoma (LSCC) patients. Current treatments, including surgical intervention, radiation therapy and chemotherapy, are moderately effective in the early-stage cases, but are less effective in more advanced cases (3). The mechanisms behind the occurrence and development of LSCC remain unclear. Therefore, a novel therapeutic strategy for the treatment of LSCC is urgently required.

Research over the past years clearly implicates multiple genetic alterations in the development and progression of laryngeal carcinoma (4). In laryngeal carcinoma, alterations in the expression profiles of several genes have been reported, including those that have important functions in cell adhesion, signal transduction, cell differentiation, metastasis, DNA repair and glycosylation (5).

B-cell-specific MLV integration site-1 (Bmi-1) has been detected in a variety of human carcinoma specimens, from the pre-cancerous to the advanced stages. In particular, Bmi-1 is overexpressed in a number of malignancies, including mantle cell lymphoma (6), B-cell non-Hodgkin's lymphoma (7), myeloid leukemia (8), non-small cell lung cancer (9), colorectal cancer (10), as well as breast and prostate cancers $(11,12)$. Recently, our group reported that Bmi-1 is also overexpressed in head and neck cancers (13), particularly in nasopharyngeal and oral cancers $(14,15)$. Gene chip analysis also showed that Bmi-l can be used to predict the rapid recurrence of a variety of cancers following treatment, as well as to predict metastasis (16), by cooperating with H-RAS in promoting breast cancer cell proliferation and invasion, resisting apoptosis, and enhancing transfer capabilities, including brain metastasis (17). Bmi-1 is a key protein responsible for cell cycle arrest in response to DNA damage and plays a role in genetic stability and cancer susceptibility. It mediates cell cycle arrest at the G1/S, S and G2/M phase to prevent the processing of damaged DNA (18).

RNA interference (RNAi) is a new technique for the effective suppression of gene expression (19). RNAi mediated by small interfering RNA (siRNA) has become an excellent tool for exploring gene function in basic research and may become a promising strategy for cancer gene therapy due to its high efficiency and specificity in blocking target gene 
expression (20-22). However, to our knowledge, siRNA targeting Bmi-1 for the treatment of laryngeal carcinoma has not been reported thus far. In this study, we designed and constructed siRNA against Bmi-1 and investigated its efficacy in suppressing Bmi-1 expression in the laryngeal carcinoma cell line, HEp-2, which expresses high levels of Bmi-1, to develop an antitumor reagent. We show that the specific downregulation of Bmi-1 by siRNA is sufficient to inhibit the growth of HEp-2 cells in vitro and in vivo. Furthermore, we explored the mechanisms through which Bmi-1 induces oncogenesis and tumor progression.

\section{Materials and methods}

Construction of lentiviral vector. We selected four different target sequences specific to Bmi-1 (Table I) with the online siRNA tool provided by Invitrogen (http://www.invitrogen. com/rnai), using the Bmi-1 reference sequence (GenBank accession no. NM 005180.5). Double-stranded DNA containing the interference sequences was synthesized according to the structure of a pGCSIL-GFP viral vector (Gikai Gene Company, Shanghai, China) (Fig. 1), and then inserted into a linearized vector. All the constructs were cloned and sequenced to confirm their structure. The positive clones were identified as lentiviral vectors that expressed human Bmi-1 short hairpin RNA (shRNA), hereinafter designated as pGCSIL/Bmi-1-A, pGCSIL/Bmi-1-B, pGCSIL/Bmi-1-C and pGCSIL/Bmi-1-D. The four lentiviral vectors were transfected into HEp-2 cells separately to evaluate their RNAi effects. We then co-transfected the pGCSIL/Bmi-1-D vector and the viral packaging system (containing an optimized mixture of two packaging plasmids, pHelper 1.0 and pHelper 2.0 vector; Gikai Gene Company) into HEp-2 cells to replicate competent lentivirus. Viral supernatant was harvested at $48 \mathrm{~h}$ after transfection, filtered through a $0.45-\mathrm{mm}$ cellulose acetate filter, and then frozen at $-70^{\circ} \mathrm{C}$. The lentivirus containing the human Bmi-1 shRNA expressing cassette (pGCSIL/Bmi-1-D) was used as the positive control for lentivirus production, denoted as Bmi-1-RNAi-LV. The pGCSIL/U6 mock vector was also packaged and used as the negative control, denoted as NC-GFP-LV. Viral concentrations were determined by serial dilution of the concentrated vector stocks in HEp-2 cells in 96-well plates. The number of green fluorescent protein (GFP)-positive cells was measured at four days post-transduction under a microscope. The titers averaged $1 \times 10^{8} \mathrm{TU} / \mathrm{ml}$.

Cell culture and lentiviral transduction of HEp-2. For lentiviral transduction, the HEp-2 cells were plated into six-well plates at a density of $1 \times 10^{6}$ cells/well. When the cells reached $30 \%$ confluence (typically on day three after subculturing), the medium was replaced with $1 \mathrm{ml}$ of fresh medium containing lentivirus at a multiplicity of infection (MOI) of 5 and $6 \mu \mathrm{g} / \mathrm{ml}$ polybrene (Gikai Gene Company). The medium was replaced with fresh medium on the following day.

Real-time reverse-transcription PCR (real-time RT-PCR). The expression of Bmi-1 mRNA in first passage untransfected or transfected HEp-2 cells was detected, with actin as the normalizing control. The specific PCR primer sequences of these genes designed by Beacon Designer 2 software were as follows: Bmi-1 forward, 5'-TGGCTCGCATTCATTTTCTG-3' and reverse,
Table I. Core target recognition sequences of siRNAs from human Bmi-1 cDNA.

\begin{tabular}{lcc}
\hline Marker & Species & Target sequence \\
\hline Bmi-1-A & Human & GGAGGAACCTTTAAAGGAT \\
Bmi-1-B & Human & CCAGAGAGATGGACTGACA \\
Bmi-1-C & Human & ACAGGAAACAGTATTGTAT \\
Bmi-1-D & Human & GGAGGAGGTGAATGATAAA \\
\hline
\end{tabular}

siRNA, small interfering RNA; Bmi-1, B-cell-specific MLV integration site-1.

Table II. Quantitative results of Bmi-1 mRNA expression by real-time PCR.

\begin{tabular}{lrr}
\hline Vector & $\Delta \Delta \mathrm{Ct}$ & \multicolumn{1}{c}{$2^{-\Delta \Delta \mathrm{Ct}}$} \\
\hline Control & $0.053 \pm 0.05$ & $0.972 \pm 0.124$ \\
NC-GFP-Bmi-1 & $-0.003 \pm 0.15$ & $0.999 \pm 0.106$ \\
Bmi-1-RNAi-LV & $-2.663 \pm 0.32$ & $0.16 \pm 0.036$ \\
\hline
\end{tabular}

Bmi-1, B-cell-specific MLV integration site-1; GFP, green fluorescent protein.

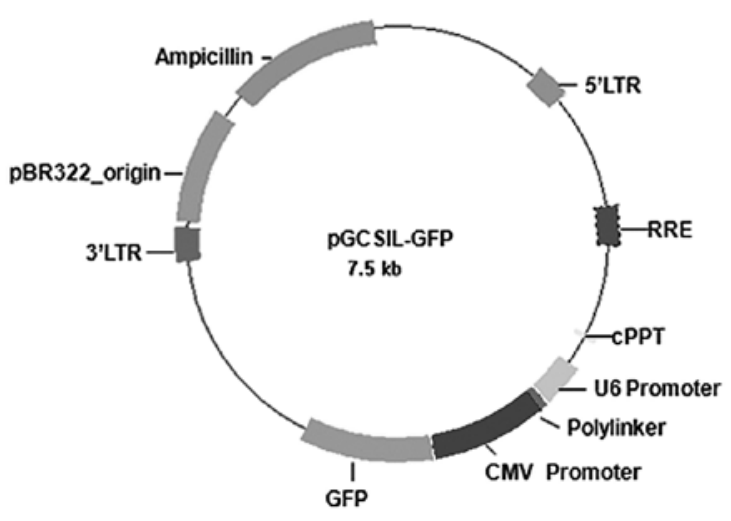

Figure 1. Design of lentiviral siRNAs. Schematic gene map of the pGCSILGFP viral vector from which the siRNA sequences were derived and cloned.

5'-AGTAGTGGTCTGGTCTT GTG-3'; actin forward, 5'-GTG GACATCCGCAAAGAC-3' and reverse, 5'-AAAGGGTGT AACGCAACTA-3'. Transduced HEp-2 cells were trypsinized and harvested at five days after transduction. Total RNA was isolated using TRIzol reagent (Invitrogen-Gibco, Grand Island, NY) and cDNA was acquired according to the M-MLV reverse transcription procedures (Promega, Madison, WI) with $2 \mu \mathrm{g}$ of total RNA. Two-step real-time RT-PCR reactions were carried out using the TP800 Real-Time PCR System (Takara), which included cycle $1(1 \mathrm{X})$ at $95^{\circ} \mathrm{C}$ for $15 \mathrm{sec}$ and cycle $2(45 \mathrm{X})$ at $95^{\circ} \mathrm{C}$ for $5 \mathrm{sec}$, and $60^{\circ} \mathrm{C}$ for $30 \mathrm{sec}$. Absorbance data were collected at the end of every extension $\left(60^{\circ} \mathrm{C}\right)$ and graphed using GraphPad Prism 4.0 software. The real-time PCR data were analyzed using the $2^{-\Delta \Delta \mathrm{Ct}}$ method (Table II). 
Western blot analysis. For western blot analysis, cells were washed three times with PBS, homogenized in cell lysis buffer (50 mmol/1 Tris, pH 7.8, $150 \mathrm{mmol} / \mathrm{l} \mathrm{NaCl}, 1 \%$ nonidet P-40) containing $10 \mu \mathrm{l} / \mathrm{ml}$ protease inhibitor (Sigma, St. Louis, MO), incubated on ice for $30 \mathrm{~min}$, and then centrifuged for $30 \mathrm{~min}$ at $10,000 \mathrm{rpm}$. The aqueous supernatant was collected and quantified using Bradford Reagent (Sigma). Individual samples, each containing $30 \mu \mathrm{g}$ of protein, were separated on a precast $12.5 \%$ SDS polyacrylamide gel in a Tris- $\mathrm{HCl}$ buffer ( $\mathrm{pH} 7.4)$ and blotted onto a polyvinylidene fluoride membrane (Bio-Rad, Hercules, $\mathrm{CA})$. The membrane was incubated at room temperature for $1 \mathrm{~h}$ in PBST buffer (PBS, pH 7.4, 0.05\% Triton X-100) containing 1\% $(\mathrm{w} / \mathrm{v})$ bovine serum albumin to block non-specific protein binding sites. After blocking, the blots were probed with a goat anti-Bmi-1 antibody (ab25791, 1:200; Abcam) overnight at $4^{\circ} \mathrm{C}$, followed by five washes with PBST. The blots were then incubated with an anti-goat IgG (1:5,000, sc-2020; Santa Cruz Biotechnology, Inc., Santa Cruz, CA) for $1 \mathrm{~h}$ at room temperature. After washing, the immunoreactive bands were detected using a chemiluminescent substrate (NEN Life Science, Inc.). Subsequently, the blots were reprobed with a mouse anti-GAPDH control antibody (1:6,000, sc32233; Santa Cruz Biotechnology, Inc.).

MTT assay. Transfected and control HEp-2 cells (5x10 $/$ well) were plated into a 96 -well plate in octuple. For six consecutive days, $20 \mu \mathrm{l}$ of MTT $(5 \mathrm{mg} / \mathrm{ml})$ were added daily to each well, and the cells were incubated at $37^{\circ} \mathrm{C}$ for an additional $4 \mathrm{~h}$. The reaction was stopped by lysing the cells with $200 \mu \mathrm{l}$ of DMSO for $5 \mathrm{~min}$. Quantification was carried out at $570 \mathrm{~nm}$ and expressed as a percentage of the control.

Cell cycle analysis by flow cytometry. Parental HEp-2 cells and control siRNA-transfected cells were harvested with $0.125 \%$ trypsin, washed twice in PBS, counted, and fixed overnight with $70 \%$ (v/v) ethanol. Cells were then centrifuged at $1,000 \mathrm{x} \mathrm{g}$ for $10 \mathrm{~min}$, resuspended at a concentration of $1 \times 10^{6} \mathrm{well} / \mathrm{ml}$ in PBS, followed by RNase incubation at $37^{\circ} \mathrm{C}$ for $30 \mathrm{~min}$. The nuclei of cells were then stained with propidium iodide (PI) for another $30 \mathrm{~min}$. A total of 10,000 nuclei were examined in a FACSCalibur flow cytometer (BD Biosciences, Franklin Lakes, NJ, USA); DNA histograms were analyzed by ModFit software.

Apoptosis detected by flow cytometry. Each of the cell lines were seeded in 24-well culture plates and divided into the following groups: Bmi-1-RNAi-LV group, negative control group and control group. Each group contained five culture flasks. When the cells reached 70-80\% confluence after $48 \mathrm{~h}$, the cells were harvested and washed in cold PBS. Annexin V and PI staining were carried out using the Annexin V-FITC Apoptosis Detection Kit (BD Biosciences) according to the manufacturer's instructions. After 20 min of incubation in the dark at room temperature, the cells were immediately analyzed by an Epics Elite ESP flow cytometer (Beckman-Coulter, Inc.).

Migration assay. The migration of the cells was assessed by a modified Boyden chamber method using microchemotaxis chambers (Transwell; Corning-Costar, Acton, MA) with a polycarbonate membrane filter $\left(8.0 \mu \mathrm{m}\right.$ pore size, $0.33 \mathrm{~cm}^{2}$ growth area). In all the experiments, both sides of the membrane were pre-coated with laminin $(5 \mu \mathrm{g} / \mathrm{ml})$ at $37^{\circ} \mathrm{C}$ for $1 \mathrm{~h}$, and then air-dried. Medium containing $10 \%$ fetal bovine serum (FBS) was added to the lower chambers as a chemoattractant. The subconfluent HEp-2 cells at passage 1, with or without Bmi-1-RNAi-LV treatment, were trypsinized and resuspended in $2 \%$ FBS to a concentration of $7 \times 10^{5}$ cells $/ \mathrm{ml}$. After $24 \mathrm{~h}$ of incubation at $37^{\circ} \mathrm{C}$, the upper surface of the membrane filters was scraped with a cotton swab to remove non-migrated cells, and then fixed with $4 \%$ paraformaldehyde for $15 \mathrm{~min}$ at room temperature. Migrating cells that passed through the Transwell filter pores and attached on the lower surface of the filters were counted in five non-overlapping fields following nuclear staining with hematoxylin. The experiments were carried out in triplicate.

Wound healing assay. Cells were cultured and grown to $100 \%$ confluence. A clear area was then scraped in the monolayer with a $200-\mu 1$ pipette tip. After washing with serum-free RPMI-1640 medium, the cells were incubated in RPMI-1640 medium containing $5 \% \mathrm{FBS}$ at $37^{\circ} \mathrm{C}$. The migration of cells into the wounded areas was evaluated at the indicated times using an inverted microscope, and then photographed. The healing rate was quantified with measurements of the gap size during culturing. Three different areas in each assay were selected to measure the distance of the migrating cells to the origin of the wound.

Colony formation analysis. Minimal concentrations of FBS (2\%) were added to the medium to measure the cell colony formation ability. Briefly, HEp-2 cells, transfected with antiBmi-1 siRNA and negative control RNA, were plated in six-well plates in RPMI-1640 supplemented with 10\% FBS at a density of 1,000 cells/well. After $4 \mathrm{~h}$, the medium was changed to FBS (2\%)-supplemented medium. After ten days of incubation at $37^{\circ} \mathrm{C}$ in an incubator under a humidified $5 \% \mathrm{CO}^{2}$ atmosphere, cells were fixed for 2 min with methanol, dyed for 20 min with $1 \%$ crystal violet, and the numbers of colonies (at least 50 cells) formed in the whole well were counted.

Determination of active caspase $-3,-8$ and -9 . The activities of caspase-3, -8 and -9 were measured using caspase-3, -8 and -9 Colorimetric Assay kits (Keygen BioTech, Nanjing, China), respectively, to determine the potential role of the caspase-3, -8 and -9 proteases in the Bmi-1-knockdown-induced apoptosis. Briefly, $1 \times 10^{6}$ cells $72 \mathrm{~h}$ after transfection were lysed at $4^{\circ} \mathrm{C}$ for $30 \mathrm{~min}$. The supernatant were then transferred to a clean microfuge tube, and protein concentration was assayed. Subsequently, $50 \mu 1$ of $2 \mathrm{X}$ reaction buffer and $5 \mu 1$ of caspase-3, -8 and -9 substrates were added, and the cells were incubated at $37^{\circ} \mathrm{C}$ for $4 \mathrm{~h}$ in the dark. The absorbance was measured at $405 \mathrm{~nm}$ on a multidetection microplate reader $\left(\right.$ Synergy ${ }^{\mathrm{TM}}$ HT; Bio-Tek, Winooski, VT). The activities of caspase-3, -8 and -9 were determined by calculating the ratio of OD $405 \mathrm{~nm}$ of the transfected cells to OD $405 \mathrm{~nm}$ of the parental cells following the instructions of the manufacturer.

In vivo tumor model. Six-week-old female athymic nude mice were subcutaneously injected with $5 \times 10^{6}$ cells in $0.2 \mathrm{ml}$ of PBS into the right scapular region. Three groups (five mice each) of mice were examined. Group 1 was injected with HEp-2 cells alone; group 2 was injected with HEp-2 cells transfected with scrambled nucleotide control siRNA (NC-GFP-LV); and 

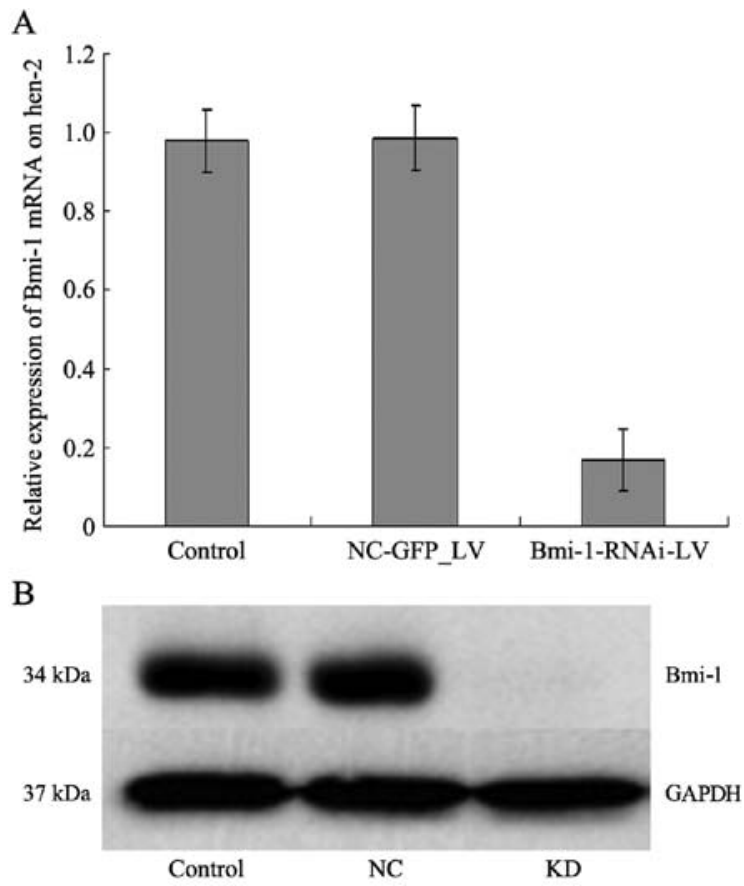

Figure 2. Bmi-1-RNAi-LV transfection silenced the mRNA and protein expression of Bmi-1 in HEp-2 cells. (A) Real-time PCR data were analyzed using the $2^{-\Delta \Delta \mathrm{Ct}}$ method. Bmi-1 mRNA expression decreased significantly in the cells transfected with Bmi-1-RNAi-LV compared to that in the untransfected cells (vs. control group, $\mathrm{t}=10.614$ ) or the cells transfected with the negative control (NC) (vs. NC-GFP-LV group, $\mathrm{t}=23.964$ ); (B) Bmi-1 protein expression detected by western blot analysis. NC, NC-GFP-LV group; KD, cells in which Bmi-1 expression was knocked down through Bmi-1-RNAi-LV transfection. Data are presented as the mean $\pm \operatorname{SEM}(\mathrm{n}=3, \mathrm{P}<0.01)$.

group 3 was injected with HEp-2 cells transfected with Bmi-1 siRNA (Bmi-1-RNAi-LV). Tumor size was measured every two days using calipers. Tumor volume was calculated with the formula $\left(\mathrm{Lx} \mathrm{W}^{2}\right) / 2$, where $\mathrm{L}$ is the length and $\mathrm{W}$ is the width. The mice were sacrificed after three weeks and the weight of the tumors was measured. The investigation conforms with the Guide for the Care and Use of Laboratory Animals published by the US National Institutes of Health (NIH Publication No. 85-23, revised 1996).

Statistical analysis. SPSS 10.0 was used for statistical analysis. One-way analysis of variance (ANOVA) was used to analyze the significance between groups. The LSD method of multiple comparisons with parental and control vector groups was used when the probability for ANOVA was statistically significant. A P-value of 0.05 was considered to indicate a statistically significant difference.

\section{Results}

Bmi-1 mRNA and protein expression. Among the four candidate target sequences screened, the lentiviral vector containing the human Bmi-1 shRNA-expressing cassette (sequence, 5'-GGAGGAGGTGAATGATAAA-3') achieved the greatest efficacy in silencing Bmi-1 expression. This construct was therefore denoted as Bmi-1-RNAi-LV; the negative control containing pGCSIL/U6 mock vector only was denoted as NC-GFP-LV. After the Bmi-1-RNAi-LV construct

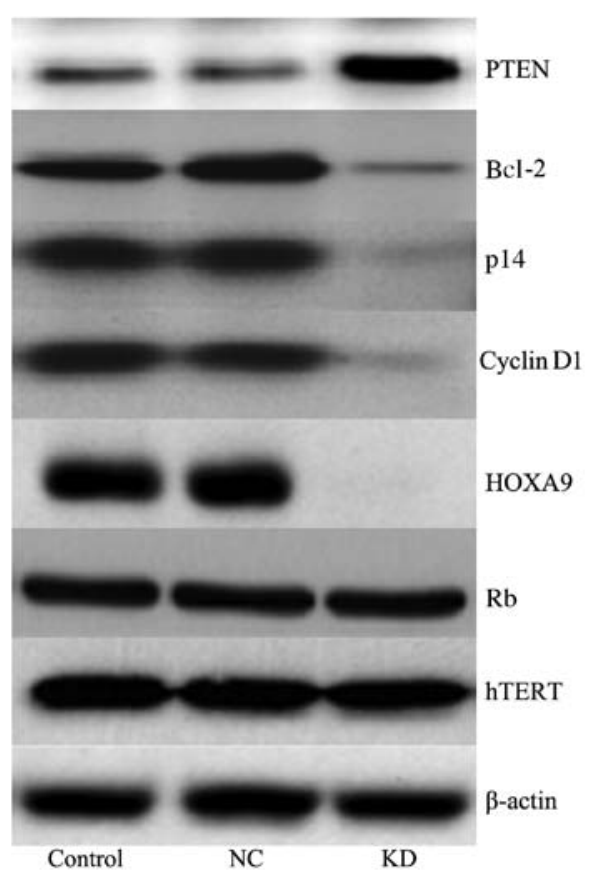

Figure 3. Western blot analysis. Representative western blots showing the levels of PTEN, Bcl-2, p14, cyclin D1, HOXA9, Rb and hTERT.

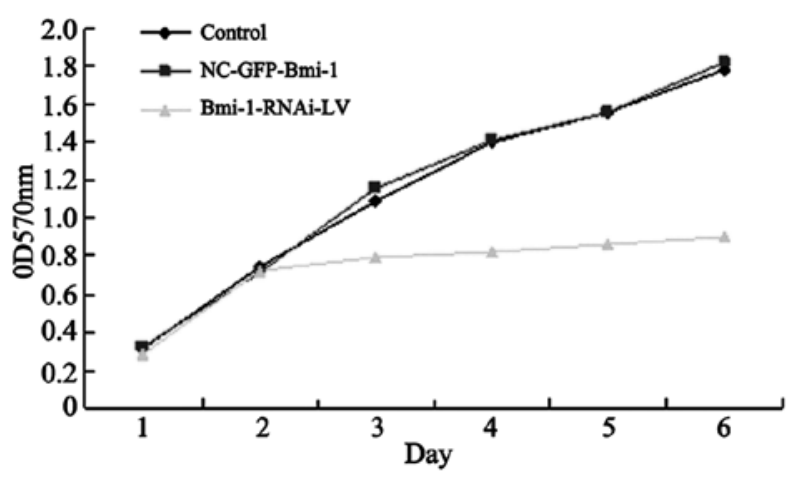

Figure 4. Cell growth curves.

was transfected into HEp-2 cells, Bmi-1 mRNA expression levels in the transfected cells were compared with those in the untransfected and control-transfected (NC-GFP-LV) HEp-2 cells by quantitative RT-PCR. As a result, cells transfected with Bmi-1-RNAi-LV showed an $80 \%$ reduction in the level of Bmi-1 mRNA expression (Fig. 2A). Bmi-1 protein expression was determined by western blot analysis to further confirm the specificity of Bmi-1-RNAi-LV-mediated Bmi-1 silencing. Bmi-1 protein expression in the cells transfected with Bmi-1RNA-LV decreased significantly compared with that of the control cells (Fig. 2B). These results indicated that lentivirusmediated RNAi is an effective method for modulating Bmi-1 expression in cultured HEp-2 cells.

No significant change $(\mathrm{P}>0.05)$ was observed in the levels of retinoblastoma $(\mathrm{Rb})$ and human telomerase reverse transcriptase (hTERT) in the cells following transfection with Bmi-1 siRNA. However, phosphatase and tensin homolog $(\mathrm{PTEN})$ levels increased significantly $(\mathrm{P}<0.05)$ and $\mathrm{Bcl}-2$, 

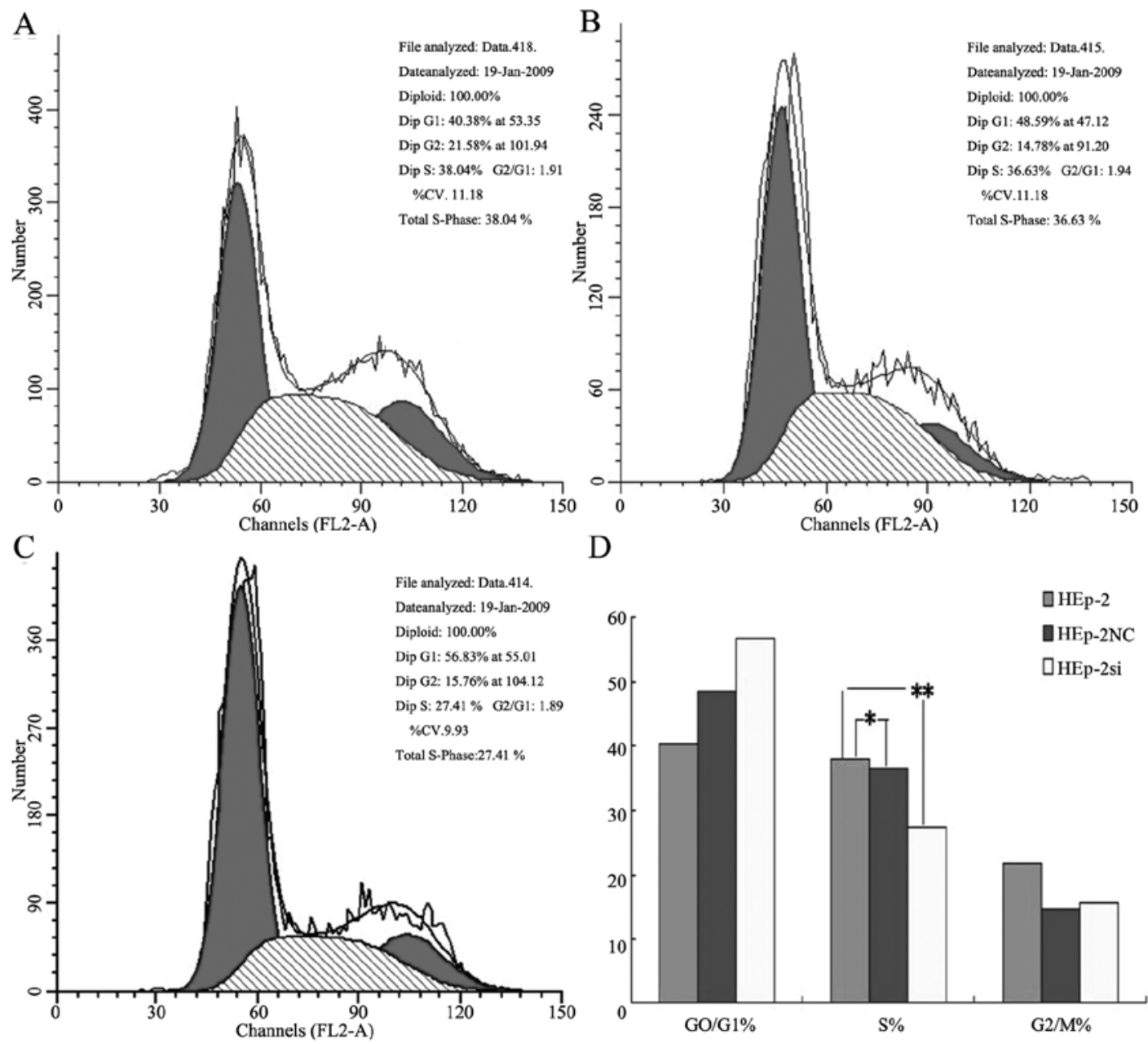

$\mathrm{D}$

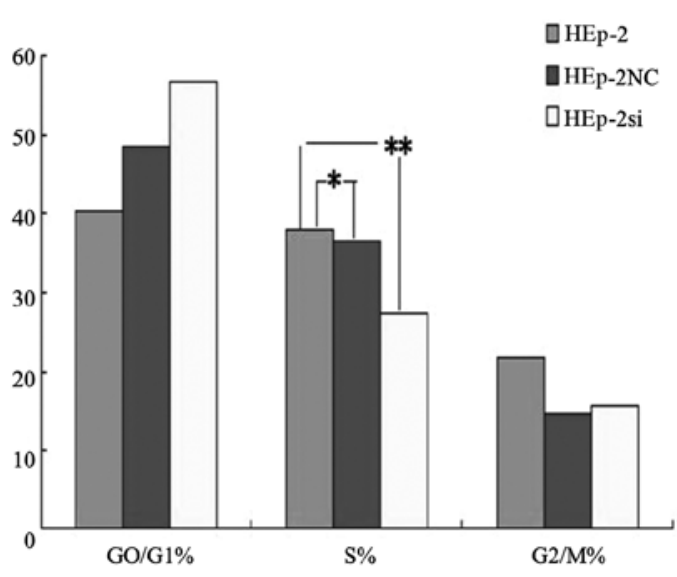

Figure 5. Cell cycle distribution analyses by flow cytometry. ${ }^{~} \mathrm{P}>0.05$ vs. scrambled nucleotide control siRNA cells. ${ }^{* *} \mathrm{P}<0.01$ vs. Bmi-1-RNAi-LV.

p14, cyclin D1 and homeobox A9 (HOXA9) levels decreased significantly $(\mathrm{P}<0.05)$ in the cells treated with Bmi-1 siRNA (Fig. 3).

Proliferation of transfected HEp-2 cells. The siRNA-transfected cells proliferated at a significantly lower rate compared to the control and parental cells, as measured by MTT assay (Fig. 4). Cell growth assay was performed, demonstrating a significant decrease in cell viability in the Bmi-1-RNAi cells compared with the control cells in a time-dependent manner, and the highest inhibitory rate was $51.25 \pm 2.86 \%$ for the HEp-2 cells on day six $(\mathrm{P}<0.05)$. However, no significant difference in cell proliferation was observed between the negative control and the control group in each cell line $(\mathrm{P}>0.05)$.

Inhibition of Bmi-1 expression increases cell apoptosis. Cell cycle distribution analysis (Fig. 5) indicated that significant changes were observed in the Bmi-1-RNAi cells, compared with the control group cells; several cells were blocked in the $\mathrm{G} 0 / \mathrm{G} 1$ phase by $87.5 \pm 2.5 \%(\mathrm{P}<0.05)$ and reduced in the $\mathrm{G} 2 / \mathrm{M}$ phase by $3.5 \pm 1.3 \%(\mathrm{P}<0.05)$, whereas no significant difference was observed in the cell cycle distribution between the negative control and control group $(P>0.05)$.

The cells were stained with Annexin V and PI to further evaluate the induction of apoptosis. The proportion of
Annexin V stained cells to the total Bmi-1 siRNA-transfected cells was increased (Fig. 6). A small amount of necrotic cells stained with PI, but not Annexin V, was also observed. The apoptotic rates in the experimental group after the cells were treated with RNAi were 21.83, 8.59 and $6.38 \%$ in the Bmi-1RNAi-LV, NC-GFP-LV group and control group, respectively. The apoptotic rate of HEp-2 cells increased to $21.83 \%(\mathrm{P}<0.05)$ following treatment with Bmi-1-RNAi-LV, whereas no obvious cell apoptosis was observed in the negatuve conrol and control group ( $\mathrm{P}>0.05)$. These results indicated that anti-Bmi-1 siRNA induced HEp-2 cells apoptosis.

Boyden chamber assay and wound healing assay. After the cultivation of the cells for $48 \mathrm{~h}$, invasions of $18.5 \pm 3.8,55.6 \pm 11.3$, and $49 \pm 13.5$ cells/field of view through the porous Transwell membranes were observed for the Bmi-1-RNAi-LV, control and NC-GFP-LV group, respectively $(\mathrm{t}=12.62, \mathrm{P}<0.01)$ (Fig. 7).

HEp-2 cells transfected with Bmi-1 siRNA had a slower wound-healing rate compared with the cells transfected with scrambled nucleotide control siRNA (NC-GFP-LV) $(0.38 \pm 0.046: 1, \mathrm{P}<0.05)$ (Fig. 8).

Activation of caspase-3, -8 and -9 via inhibition of Bmi-1 expression. The activities of caspase- $-3,-8$ and -9 in the HEp- 2 cells transfected with Bmi-1 siRNA or with nega- 

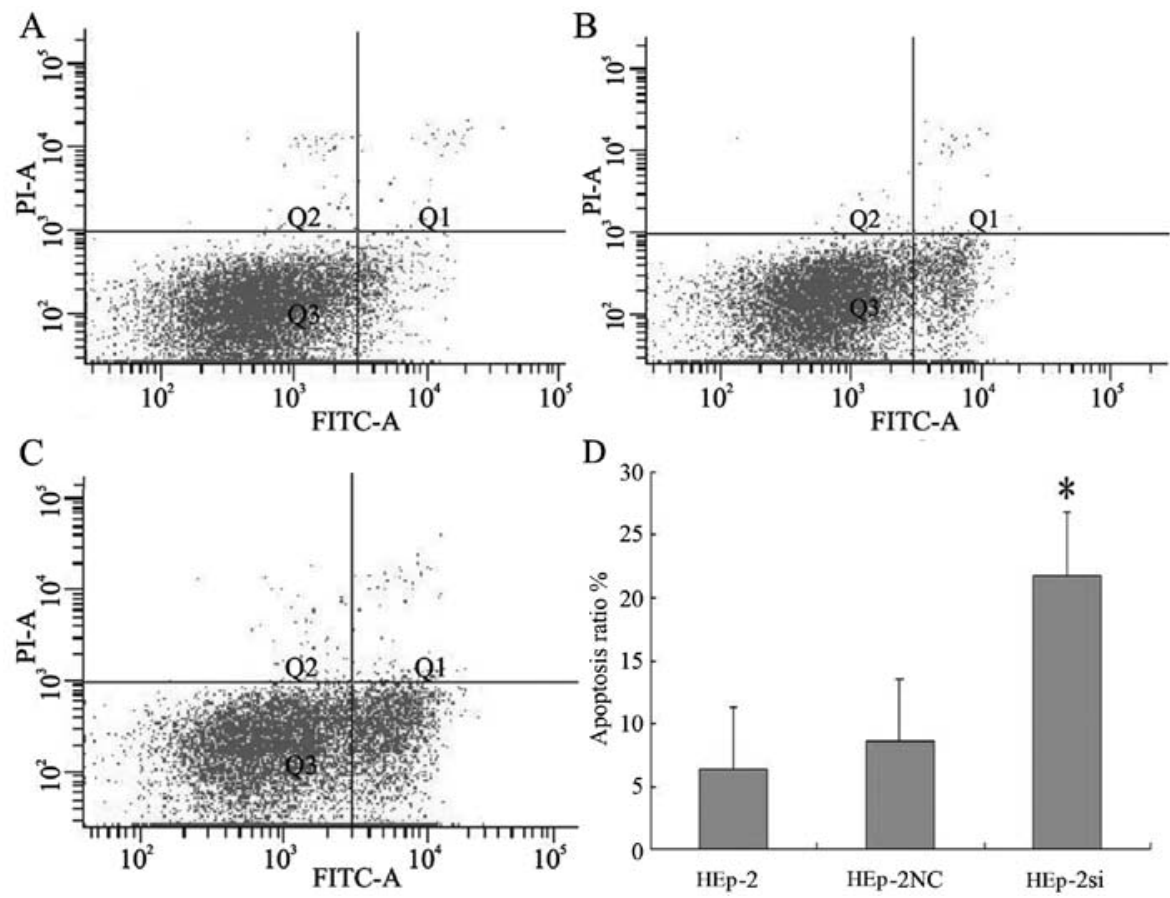

Figure 6. Effects of anti-Bmi-1 siRNA on HEp-2 cells discriminated by (A) Annexin V/PI double staining, (B) HEp-2 cells transfected with mock (control), (C) scrambled nucleotide control siRNA (NC-GFP-LV), and (D) HEp-2 cells transfected with Bmi-1 siRNA (Bmi-1-RNAi-LV). Graph shows the apoptotic ratio in the Bmi-1-RNAi-LV group. ${ }^{*} \mathrm{P}<0.01$ vs. control.

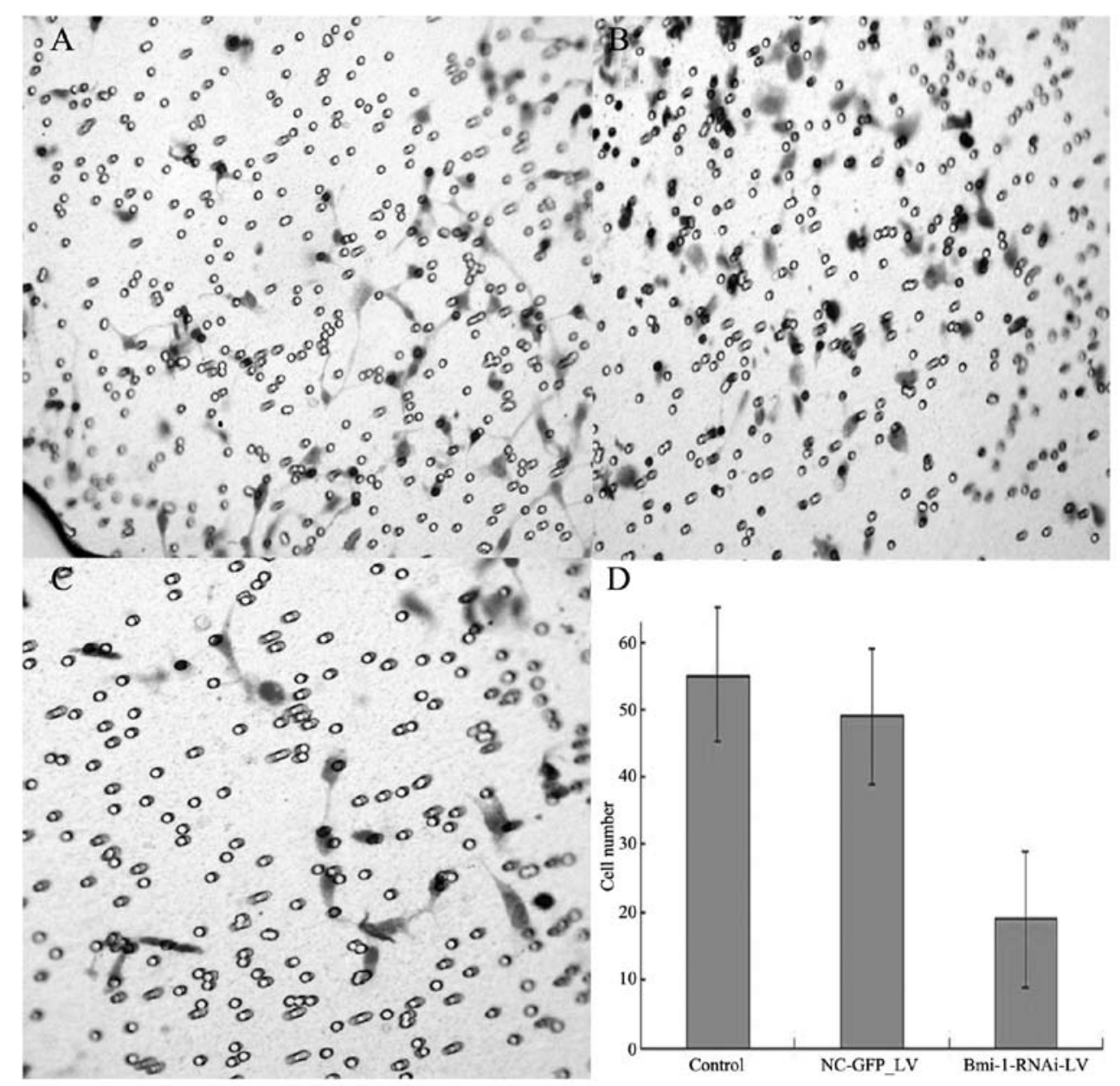

Figure 7. Effect of Bmi-1 silencing on the migration of HEp-2 cells. (A) HEp-2 cells transfected with mock (control). (B) Scrambled nucleotide control siRNA (NC-GFP-LV). (C) HEp-2 cells transfected with Bmi-1 siRNA (Bmi-1-RNAi-LV). (D) Statistical analyses revealed that Bmi-1 knockdown by Bmi-1-RNAi-LV transfection (Bmi-1 KD groups) significantly inhibited cell motility. 

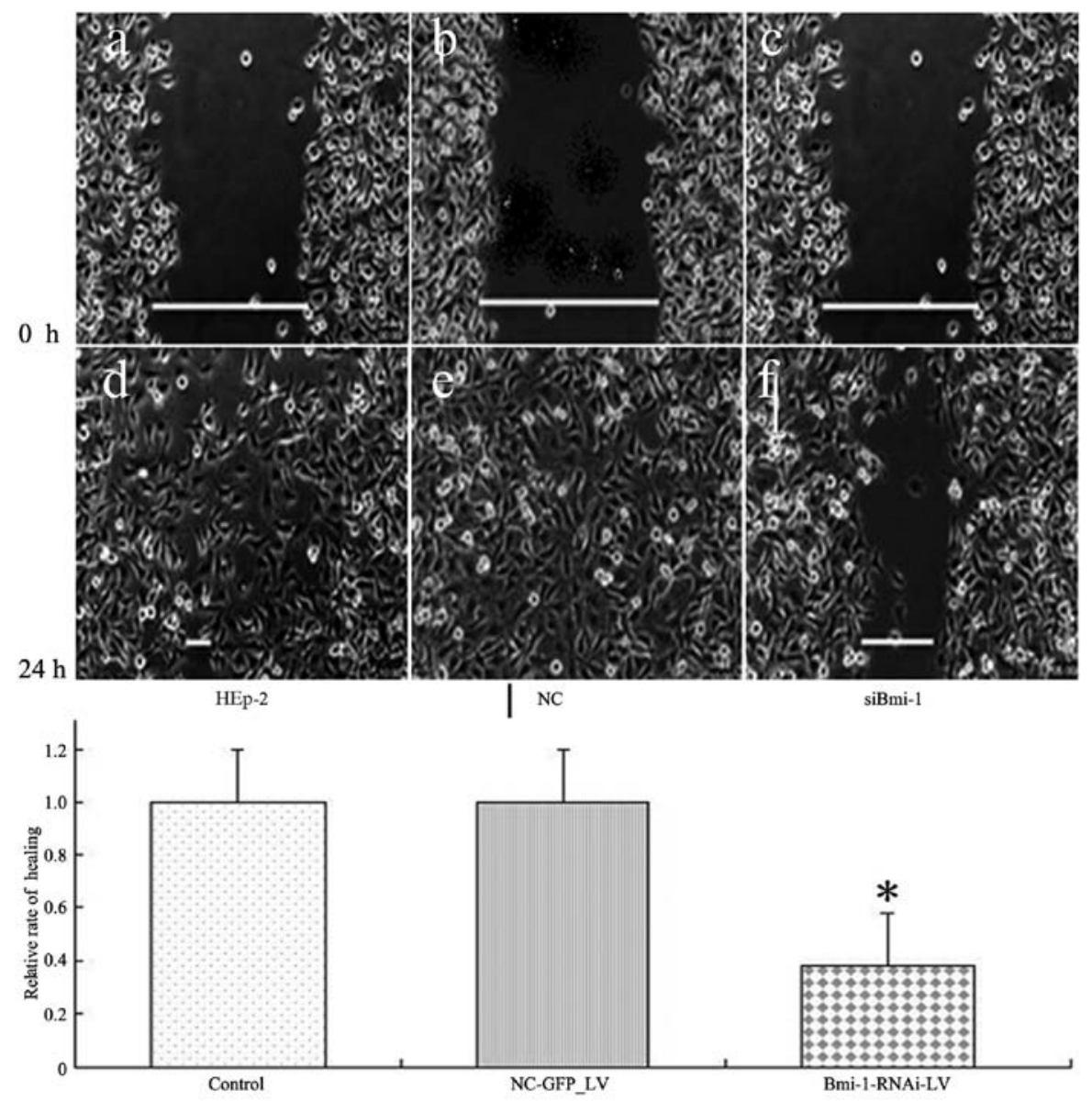

Figure 8. Wound healing assay determined the migration rate of HEp-2 cells transfected with mock, scrambled nucleotide control siRNA (NC-GFP-LV), and HEp-2 cells transfected with Bmi-1 siRNA (Bmi-1-RNAi-LV) cells. Migration of the cells to the wound was visualized at $24 \mathrm{~h}$ under an inverted Olympus phase-contrast microscope $(\mathrm{x} 100)$. The healing rate of the HEp-2 cells transfected with mock cells was normalized to that of the scrambled nucleotide control siRNA cells ( $\mathrm{P}<0.05$, relative to scrambled nucleotide control siRNA cells).

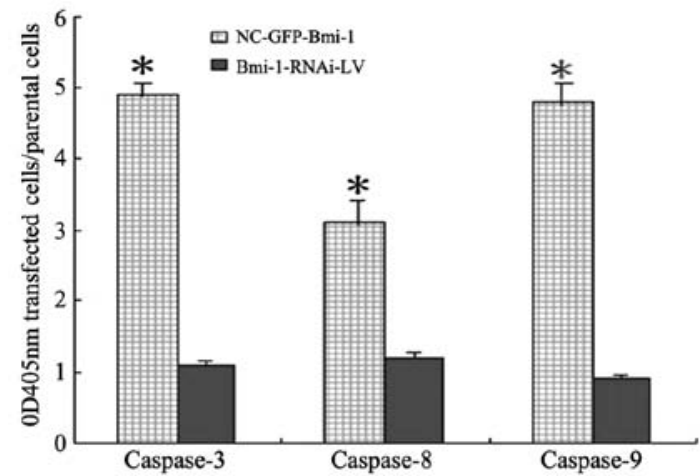

Figure 9. Colorimetric assay of caspase-3, -8 and -9 activity at $72 \mathrm{~h}$ after transfection. Data are presented as the means \pm SE from three independent experiments $\left({ }^{*} \mathrm{P}<0.01\right.$ vs. control).

tive RNA were examined (Fig. 9) by colorimetric assay. In addition to executioner caspase-3, initiator caspase- 8 and -9 are also important for apoptosis. The ratio of OD $405 \mathrm{~nm}$ of the transfected cells to OD $405 \mathrm{~nm}$ of the scrambled nucleotide control siRNA cells was calculated. The OD value of caspase- 3 and -9 was approximately 4 and that of caspase- 8 was approximately 2 .
Downregulation of Bmi-1 inhibits the tumorigenicity of HEp-2 cells in vivo. Tumor volume was measured every two days until the mice were sacrificed on day 21 . The mice in group 3 had substantially smaller tumors compared to the mice in the other two groups (Fig. 10). At the time of sacrifice, the tumor volume for the mice injected with Bmi-1-RNAi-LV was $274.68 \pm 154.79 \mathrm{~mm}^{3}$ compared with $664.31 \pm 246.30 \mathrm{~mm}^{3}$ for the mice injected with HEp-2 cells $(\mathrm{P}=0.003)$ or $643.67 \pm 270.12 \mathrm{~mm}^{3}$ for the mice in the negative control group $(\mathrm{P}=0.008)$. In addition, the mean tumor weight at the end of the experiment was significantly lower in the Bmi-1-RNAi-LV group $(0.58 \pm 0.12 \mathrm{~g})$ compared to that in the negative control $(1.15 \pm 0.19 \mathrm{~g}, \mathrm{P}=0.005)$ or the control group $(0.98 \pm 0.20 \mathrm{~g}, \mathrm{P}=0.007)$.

TUNEL assay. TUNEL assay showed that groups 1 and 2 had scattered apoptotic cells, whereas group 3 showed a large number of apoptotic cells (x400) compared with the HEp-2 and negative control group $(\mathrm{P}<0.05)$ (Fig. 11).

Western blot analysis. The western blot analysis results showed the significant inhibitory effect of Bmi-1 lentiviral-mediated RNAi on Bmi-1, cyclin D1 and p14 protein expression. Bmi-1, cyclin D1 and p14 protein expression in the HEp-2 cells transfected with Bmi-1 lentiviral-mediated RNAi was significantly decreased (Fig. 12). 


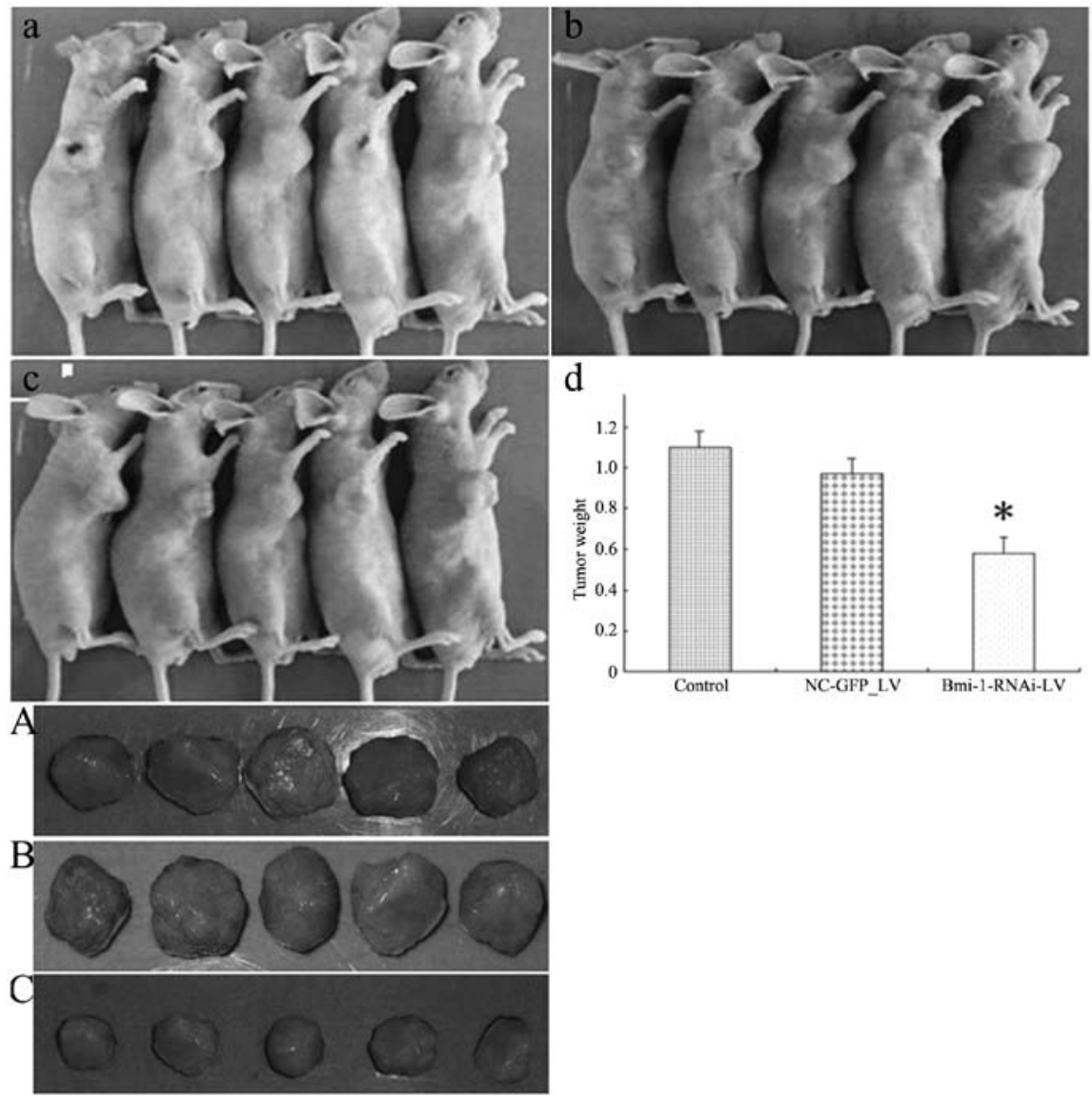

Figure 10. Knockdown of Bmi-1 inhibits HEp-2 xenograft tumor growth. Three groups of nude mice (each group contained five mice) were injected into the right scapular region with (a) HEp-2 cells transfected with mock (control), (b) HEp-2 cells transfected with scrambled nucleotide control siRNA (NC-GFP-LV), and (c) HEp-2 cells transfected with Bmi-1 siRNA (Bmi-1-RNAi-LV). (d) Statistical analyses revealed that the mean tumor weight at the end of the experiment was significantly lower in the Bmi-1-RNAi-LV group than in the negative control (NC) group or control group $(0.58 \pm 0.12$ vs. $1.15 \pm 0.19$ and $0.98 \pm 0.20 \mathrm{~g}$, respectively, ${ }^{*} \mathrm{P}=0.005$ or $\left.\mathrm{P}=0.007\right)$. Bottom left panel shows the size of the tumors extracted from the three groups of mice (A) tumors from mice injected with HEp-2 cells transfected with mock (control), (B) tumors from mice injected with HEp-2 cells transfected with scrambled nucleotide control siRNA (NC-GFP-LV), and (C) tumors from mice injected with HEp-2 cells transfected with Bmi-1 siRNA (Bmi-1-RNAi-LV).

\section{Discussion}

Laryngeal carcinoma accounts for 1 to $5 \%$ of all tumors, and is the second most common cancer of the respiratory system (next to lung cancer). It is also the second most common epithelial malignancy in the head and neck region (next to nasopharyngeal cancer), and accounts for 7.9 to $35 \%$ of all ear, nose and throat (ENT) malignancies (23). If treated early, the prognosis of laryngeal carcinoma is good, with a five-year survival rate of $90 \%$ and the possibility of retaining laryngeal functions (24). However, the prognosis of late-stage laryngeal carcinoma is poor due to tumor invasion and metastasis. The five-year survival rate is below $60 \%$, and patients usually succumb to the diseased due to local recurrence, neck lymph node recurrence, or distant metastasis $(25,26)$. The molecular mechanisms behind the development and progression of laryngeal carcinoma are poorly understood.

Bmi-1 plays a critical role in the immortalization of normal epithelial cells and early malignant transformation, as well as in the maintenance of the self-renewal of stem cells.

Polycomb group (PcG) proteins play an important role as epigenetic gene silencers during development (27). In addi- tion to their role in development, these proteins have been reported to be overexpressed in a variety of human cancers, such as malignant lymphomas and various solid tumors (28). In particular, Bmi-1 is overexpressed in a number of malignancies, such as mantle cell lymphoma (6), B-cell nonHodgkin's lymphoma (9), myeloid leukemia (8), non-small cell lung cancer (29), colorectal cancer (10), as well as breast and prostate cancers $(16,12)$. In addition, we recently reported that Bmi-1 is also overexpressed in laryngeal carcinoma (30). Our present study demonstrates that a significant difference in Bmi-1 expression at both the protein and mRNA level exists between laryngeal carcinoma cells and the adjacent normal laryngeal tissue.

In the present study, we designed and constructed a siRNA recombinant expression vector targeting Bmi-1 to investigate its effect on laryngeal carcinoma cell proliferation. Cell proliferation was significantly inhibited after the cells were treated with RNAi. We demonstrate that lentiviruses can efficiently deliver Bmi-1 siRNAs into HEp-2 cells and that the transfection of Bmi-1 shRNA virtually eliminates Bmi-1 protein expression, indicating that siRNA sequences targeting Bmi-1 may be a potential therapeutic strategy for the gene therapy of 

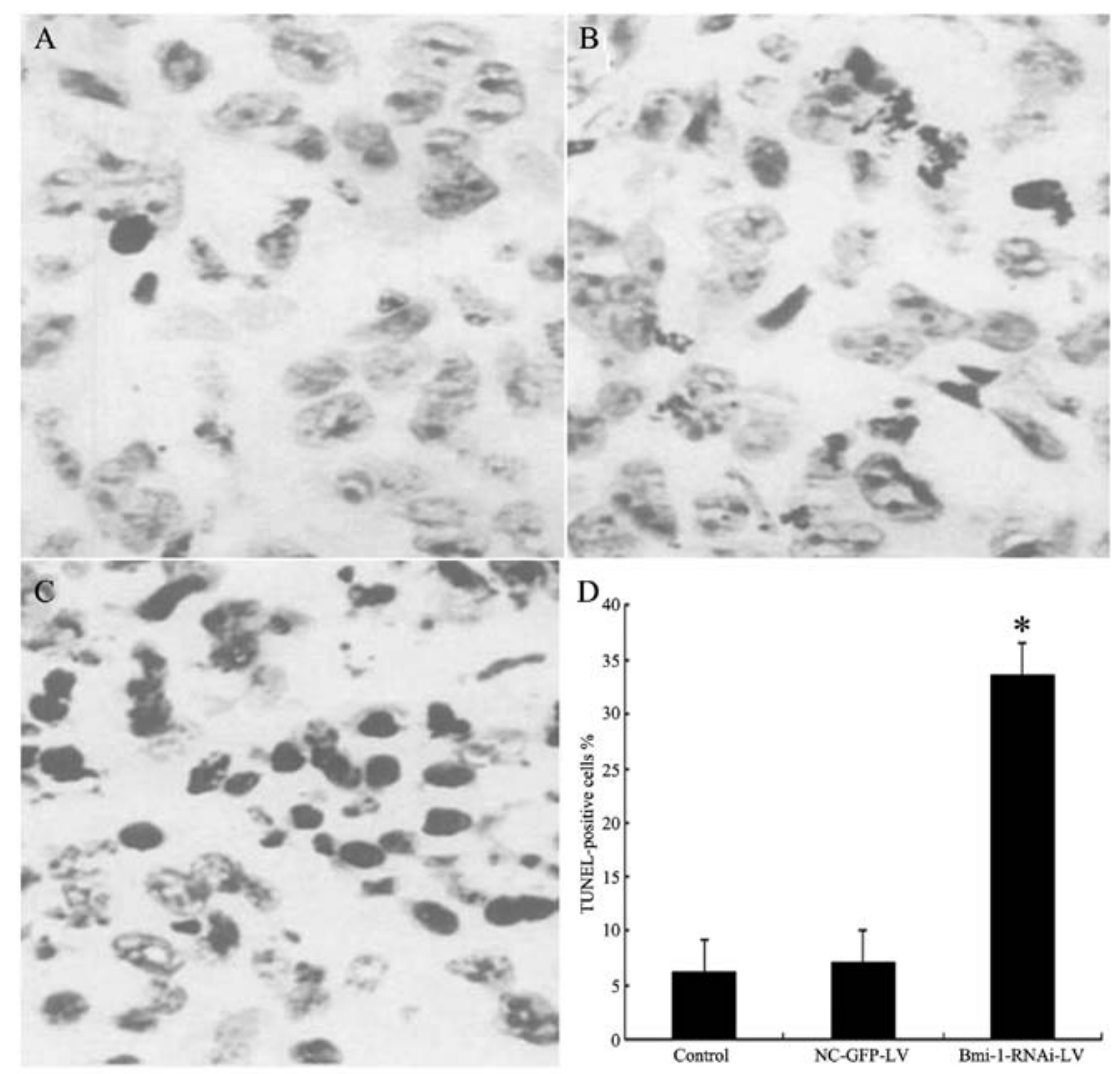

Figure 11. siRNA against Bmi-1 increases cell apoptosis in vivo. HEp-2 cells transfected with Bmi-1 siRNA, scrambled nucleotide control siRNA or mock (control) were injected into nude mice. TUNEL assay was used to detect apoptotic cells in situ. Dark staining of nuclei indicates apoptosis. Representative TUNEL-positive cells are shown. (A) HEp-2 cells transfected with Bmi-1 siRNA (Bmi-1-RNAi-LV), (B) HEp-2 cells transfected with scrambled nucleotide control siRNA (NC-GFP-LV), (C) HEp-2 cells transfected with mock (control). (D) The percentages of TUNEL-positive cells were scored for HEp-2 cells transfected with Bmi-1 siRNA, scrambled nucleotide control siRNA or mock control. "P<0.01 vs. control.

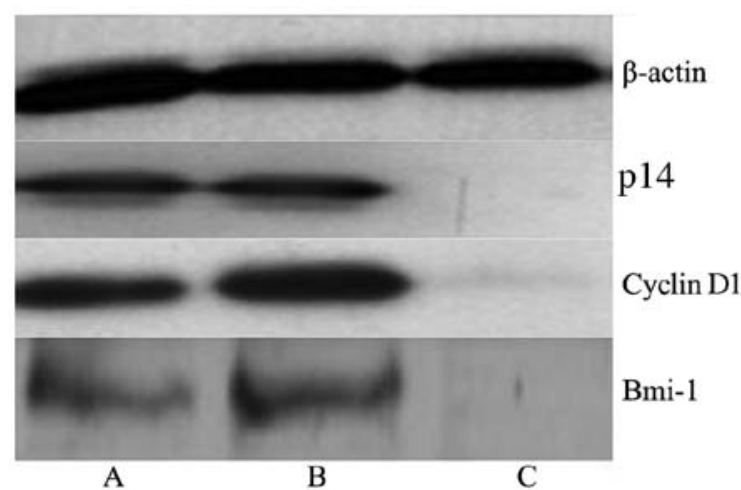

Figure 12. Western blot analysis for determining the levels of Bmi-1, p14 and cyclin D1 in HEp-2 xenograft tumors. Lane A, control group; lane B, NC-GFP-LV groiup; and lane C, Bmi-1-RNAi-LV group.

LSCC. Previous studies have reported that the downregulation of Bmi-1 by the adenovirus-mediated delivery of Bmi-1 siRNA reduces the invasion, angiogenesis and metastasis of lung cancer cells (31). Moreover, the adenovirus-mediated expression of Bmi-1 siRNA in human lung xenografts in vivo has been shown to result in increased immunostaining of Fas, Fas-L, cleaved Bid and TIMP-3, which in turn promotes apoptosis in lung cancer (32).
The initiation and progression of laryngeal carcinoma involve a series of genetic events, including the activation of oncogenes and the inactivation of tumor suppressors (33).

The regulatory mechanism of the PcG proteins relies upon epigenetic modifications of specific histone tails that are inherited through cell division $(34,35)$. Bmi-1 is a member of the PcG family, thus, Bmi-1 overexpression can repress the p16Ink4a (CDKN2A) and p19Arf targets $(10,15)$. In the absence of p16Ink4a, the cyclin D/Cdk4/6 complex can phosphorylate $\mathrm{pRb}$, allowing the E2F-dependent transcription, which leads to cell cycle progression and DNA synthesis. Bmi-1-deficient mouse embryonic fibroblasts overexpress the INK4a/ARF locus-encoded genes, CDKN2A and p19ARF (mouse homologue of human p14ARF), and undergo premature senescence in culture (36).

Previous studies using in vivo mouse and in vitro cell culture models have shown that Bmi-1 regulates the expression of the INK4A/ARF locus, which encodes two important tumor suppressors, namely, p16INK4A and p19ARF (p14ARF in humans) (36,37). Bmi-1 can potentially regulate the p16-pRb and p53-p21 pathways of senescence by downregulating p16INK4A and p19ARF (38).

PTEN regulates multiple signal transduction pathways, involved in the inhibition of proliferation and migration. PTEN exerts a variety of tumor suppressive effects, on various downstream signaling pathways, such as the $\mathrm{pI} 3 \mathrm{~K} /$ AKT pathway, and regulates gene transcription and protein 
translation, inducing apoptosis and promoting cell cycle arrest.

Bmi-1 expression is regulated by the cell cycle and the highest expression is observed in the G2/M phase (39). Our data showed that suppressing the expression of Bmi-1 in HEp-2 cells significantly inhibits cell proliferation and induces spontaneous cell apoptosis and G0/G1 cell cycle arrest. These results are in accordance with thos form previous studies on esophageal carcinoma cells (40) and cervical carcinoma cells. These data suggest that Bmi-1 plays an important role in the development of laryngeal carcinoma.

The suppression of Bmi-1 expression by lentiviralmediated RNAi, induces cell cycle arrest at the G1 phase of the cell cycle and promotes apoptosis. Thus, this method of suppressing Bmi-1 expression which leads to cell growth inhibition and the induction of apoptosis, in turn reduces the number of proliferating cells, abnormal proliferation and suppresses the growth of laryngeal carcinoma cells; thus it has a significant therapeutic effect.

In the present study, BALB/c nude mice were injected with HEp-2 laryngeal carcinoma cells transfected with Bmi-1 siRNA (Bmi-1-RNAi-LV). The results showed that both the average tumor weight and volume were significantly lower in the Bmi-1-RNAi-LV-treated group than those in the control group. The study by Abdouh showed that downregulating the expression of Bmi-1 by lentiviral shRNA led to the decline of colony formation and glioma growth both in vitro and in vivo (41), which is consistent with our findings.

Our results demonstrated that Bmi-1 gene silencing cannot eliminate the tumor completely, suggesting that Bmi-1 is not the only protease involved in the invasion and growth of LSCC. The functions of Bmi-1 associated with stem cells in head and neck cancer have not yet been fully elucidated. It is also important to investigate the associated genes and signal transduction pathways in order to effectively contribute to the gene targeted therapy of head and neck tumors, thus increasing the possibility of developing a more potent therapy for head and neck tumors.

We directly approached the important role of Bmi-1 in the invasion and growth of LSCC by analyzing the effects of stable Bmi-1 silencing by recombinant lentivirus-mediated shRNA. To our knowledge, we demonstrate for the first time the inhibition of Bmi-1 expression by lentivirus-mediated shRNA, suggesting that Bmi-1 may be a candidate gene for the gene targeted therapy of human LSCC.

\section{Acknowledgements}

The present study was supported by a grant from the Science and Technology Project of Shanxi Province (no. 2010D40).

\section{References}

1. Marioni G, Marchese-Ragona R, Cartei G, Marchese F and Staffieri A: Current opinion in diagnosis and treatment of laryngeal carcinoma. Cancer Treat Rev 32: 504-515, 2006.

2. Papadas TA, Alexopoulos EC, Mallis A, Jelastopulu E, Mastronikolis NS and Goumas P: Survival after laryngectomy: a review of 133 patients with laryngeal carcinoma. Eur Arch Otorhinolaryngol 267: 1095-1101, 2010.

3. Sun YN, Liu M, Yang B, Li B and Lu J: Role of siRNA silencing of MMP-2 gene on invasion and growth of laryngeal squamous cell carcinoma. Eur Arch Otorhinolaryngol 265: 1385-1391, 2008.
4. Zhao JX and Xie XL: Regulation of gene expression in laryngeal carcinama by microRNAs. Int J Pathol Clin Med 32: 222-225, 2012.

5. Srivastava R (ed): Apoptosis, Cell Signaling, and Human Diseases. Molecular Mechanisms. Vol. 1. Humana Press, Totowa, 2007.

6. Bea S, Tort F, Pinyol M, et al: BMI-1 gene amplification and overexpression in hematological malignancies occur mainly in mantle cell lymphomas. Cancer Res 61: 2409-2412, 2001.

7. Bhattacharyya J, Mihara K, Ohtsubo M, et al: Overexpression of BMI-1 correlates with drug resistance in B-cell lymphoma cells through the stabilization of survivin expression. Cancer Sci 103: 34-41, 2012.

8. Sawa M, Yamamoto K, Yokozawa T, et al: BMI-1 is highly expressed in M0-subtype acute myeloid leukemia. Int $\mathbf{J}$ Hematol 82: 42-47, 2005.

9. Kimura M, Takenobu H, Akita N, et al: Bmil regulates cell fate via tumor suppressor WWOX repression in small-cell lung cancer cells. Cancer Sci 102: 983-990, 2011.

10. Kim JH, Yoon SY, Kim CN, et al: The Bmi-1 oncoprotein is overexpressed in human colorectal cancer and correlates with the reduced p16INK4a/p14ARF proteins. Cancer Lett 203: 217-224, 2004.

11. Glinsky GV, Berezovska O and Glinskii AB: Microarray analysis identifies a death-from-cancer signature predicting therapy failure in patients with multiple types of cancer. J Clin Invest 115: 1503-1521, 2005.

12. Song W, Tao K, Li H, et al: Bmil is related to proliferation, survival and poor prognosis in pancreatic cancer. Cancer Sci 101: 1754-1760, 2010

13. Yao X, Wang X, Zhang S and Zhu H: Effects of Bmi-1 RNAi gene on laryngeal carcinoma Hep-2 cells. Lin Chung Er Bi Yan Hou Tou Jing Wai Ke Za Zhi 26: 550-557, 2012 (In Chinese).

14. Kang MK, Kim RH, Kim SJ, et al: Elevated Bmi-1 expression is associated with dysplastic cell transformation during oral carcinogenesis and is required for cancer cell replication and survival. Br J Cancer 96: 126-133, 2007.

15. Song LB, Zeng MS, Liao WT, et al: Bmi-1 is a novel molecular marker of nasopharyngeal carcinoma progression and immortalizes primary human nasopharyngeal epithelial cells. Cancer Res 66: 6225-6232, 2006.

16. Glinsky GV: Death-from-cancer signatures and stem cell contribution to metastatic cancer. Cell Cycle 4: 1171-1175, 2005.

17. Hoenerhoff MJ, Chu I, Barkan D, et al: BMI1 cooperates with $\mathrm{H}-\mathrm{RAS}$ to induce an aggressive breast cancer phenotype with brain metastases. Oncogene 28: 3022-3032, 2009.

18. Xu CR, Lee SS, Ho C, et al: Bmil functions as an oncogene independent of Ink4A/Arf repression in hepatic carcinogenesis. Mol Cancer Res 7: 1937-1945, 2009.

19. Elbashir SM, Harborth J, Lendeckel W, et al: Duplexes of 21-nucleotide RNAs mediate RNA interference in cultured mammalian cells. Nature 411: 494-498, 2011.

20. Mittal V: Improving the efficiency of RNA interference in mammals. Nat Rev Genet 5: 355-365, 2004.

21. Moffat J and Sabatini DM: Building mammalian signalling pathways with RNAi screens. Nat Rev Mol Cell Biol 7: 177-187, 2006.

22. Kim DH and Rossi JJ: Strategies for silencing human diseaseusing RNA interference. Nat Rev Genet 8: 173-184, 2007.

23. Huang XZ and Wang JB: Practical otolaryngology. People's Medical Publishing House, Beijing, pp502-503, 1998.

24. Tu Gy, Tang PZ and Jia CY: Horizontovertical laryngectomy for supraglottic carcinoma. Otolaryngol Head Neck Surg 117: 280-286, 1997.

25. Sessions DG, Lenox J, Spector GJ, et al: Management of T3NOM0 glottic carcinoma: therapeutic outcomes. Laryngoscope 112: 1281-1288, 2002.

26. Liu YZ, Tang PZ, Qi YF and Xu Z: The management of stomal recurrence after laryngectomy. Zhonghua Er Bi Yan Hou Ke Za Zhi 37: 380-383, 2002 (In Chinese).

27. Ringrose L and Paro R: Epigenetic regulation of cellular memory by the Polycomb and Trithorax group proteins. Annu Rev Genet 38: 413-443, 2004.

28. Raaphorst FM: Deregulated expression of Polycomb-group oncogenes in human malignant lymphomas and epithelial tumors. Hum Mol Genet 14: R93-R100, 2005.

29. Kikuchi J, Kinoshita I, Shimizu Y et al: Distinctive expression of the polycomb group proteins Bmil polycomb ring finger oncogene and enhancer of zeste homolog 2 in nonsmall cell lung cancers and their clinical and clinicopathologic significance. Cancer 116: 3015-3024, 2010. 
30. Yao XB, Wang XX, Zhang SQ, Yan LY and Zhu HL: Association of Bmi-1 mRNA overexpression with differentiation, metastasis and prognosis of laryngocarcinoma. Xi'An Jiaotong Daxue Xuebao 32: 246-249, 2011 (In Chinese).

31. Wang YX, Wei YM, Wang XH and Zhu XY: Construction of eukaryotic expression vector targeting Bmi-1 and its influences on proliferation of SW480 cells. Xian Dai Sheng Wu Yi Xue Jin Zhan 9: 2270-2272, 2009 (In Chinese).

32. Wang ZX, Lu BB, Yang JS, Wang KM and De W: Adenovirusmediated siRNA targeting $\mathrm{c}$-Met inhibits proliferation and invasion of small-cell lung cancer (SCLC) cells. J Surg Res 171: $127-135,2011$.

33. Li PH, Wang HJ, Liu W and Xu XG: PRDM1 gene expression in laryngeal carcinoma and its clinical significance. Head Neck Surg 24: 179-180, 2010.

34. Pirrotta V: Polycombing the genome: PcG, trxG, and chromatin silencing. Cell 93: 333-336, 1998.

35. Orlando V: Polycomb, epigenomes, and control of cell identity. Cell 112: 599-606, 2003.

36. Jacobs JJ, Kieboom K, Marino S, Depinho RA and van Lohuizen M: The oncogene and Polycomb-group gene bmi-1 regulates cell proliferation and senescence through the ink4a locus. Nature 397: 164-168, 1999.
37. Itahana K, Zou Y, Itahana Y, et al: Control of the replicative life span of human fibroblasts by 16 and the polycomb protein Bmi-1. Mol Cell Biol 23: 389-401, 2003.

38. Dimri GP: What has senescence got to do with cancer? Cancer Cell 7: 505-512, 2005

39. Xu Z, Liu H, Lv X, Liu Y, Li S and Li H: Knockdown of the Bmi-1 oncogene inhibits cell proliferation and induces cell apoptosis and is involved in the decrease of Akt phosphorylation in the human breast carcinoma cell line MCF-7. Oncol Rep 25: 409-418, 2011.

40. Liu WL, Guo XZ, Zhang LJ, et al: Prognostic relevance of Bmi-1 expression and autoantibodies in esophageal squamous cell carcinoma. BMC Cancer 10: 467, 2010.

41. Abdouh M, Facchino S, Chatoo W, et al: BMI1 sustains human glioblastoma multiforme stem cell renewal. J Neurosci 29: 8884-8896, 2009. 